\title{
EFFECT OF RAINFALL ON THE MOVEMENT AND PERSISTENCE OF METSULFURON-METHYL AND CLOPYRALID APPLIED TO PASTURE
}

\author{
T.K. JAMES, A. RAHMAN, J.M. MELLSOP and M. TROLOVE \\ AgResearch, Ruakura Research Centre, Private Bag 3123, Hamilton \\ Corresponding author: trevor.james@agresearch.co.nz
}

\begin{abstract}
Metsulfuron-methyl and clopyralid are two herbicides frequently used in pasture. The mobility and persistence of both have been previously reported and showed great variation between overseas and New Zealand results. In a field trial the effect of simulated rain within the first 7 days of herbicide application on the persistence and movement of these chemicals was studied using bioassay methods. Results show that $15 \mathrm{~mm}$ of simulated rain on either Day 1, 3 or 7 after herbicide application had no apparent effect on the dissipation of metsulfuron-methyl but natural rainfall that occurred later in the experiment leached it to the $50-100 \mathrm{~mm}$ soil layer. Glasshouse bioassays of soil samples collected from the field showed that between $75 \%$ and $90 \%$ of the applied herbicide had degraded by Day 56. Clopyralid stayed in the top $50 \mathrm{~mm}$ of soil during the experiment but by Day 56 less than $10 \%$ of the applied herbicide remained.
\end{abstract}

Keywords: metsulfuron-methyl, clopyralid, bioassay, persistence, rainfall.

\section{INTRODUCTION}

The herbicides metsulfuron-methyl and clopyralid are both registered for use in pastures (O’Connor 2004). Metsulfuron-methyl is used for controlling scrub weeds and many herbaceous broadleaf weeds. The latter require special application techniques such as carpet wipers and spot treatment to protect the broadleaf pasture species (James et al. 1999). Clopyralid is registered for controlling thistles in pastures and for general broadleaf weed control in turf. In pasture it is usually used at low rates in combination with a phenoxy herbicide such as MCPA or 2,4-D but in turf it is frequently used alone and at higher rates.

In some environments metsulfuron-methyl has been reported as both highly persistent and highly mobile (Sarmah et al. 2000). These situations are usually associated with alkaline, low organic matter soils that are quite different to most New Zealand soils. Previous work in New Zealand soils has demonstrated metsulfuron-methyl to be only moderately mobile with short to medium persistence (James et al. 1995; Rahman et al. 1991; Rahman et al. 1997). In a series of field trials around New Zealand, James \& Rahman (2001) found that persistence of $12 \mathrm{~g} /$ ha metsulfuron-methyl ranged from 28 days to more than 63 days and postulated that the shorter persistence could have been the result of rain within the first 7 days after application.

Clopyralid has also been demonstrated to be very persistent in some instances, with residues still detected after 287 days when applied to bare ground (Tanphiphat \& Burrill 1987). However, work in New Zealand has shown that it is considerably less persistent when applied to pasture (Rahman et al. 1981; Ahmad et al. 2003).

The objective of this study was to test the hypothesis that rainfall within 7 days of application enhances the dissipation of metsulfuron-methyl and clopyralid from the root zone. Sampling different depth fractions in the soil was used to determine whether the dissipation was due to enhanced degradation or to more rapid leaching. 


\section{MATERIALS AND METHODS}

The trial was located at the Waikato Research Orchard near Hamilton on a Horotiu silt loam soil. The site was in permanent pasture that was mown to about $20 \mathrm{~mm}$ height prior to herbicide application. The trial was laid out to a fully randomised split-plot design with 4 replicates and individual plot size of $3 \times 8 \mathrm{~m}$ with $2 \mathrm{~m}$ headlands. The main treatments comprised a single rate of the two herbicides and an untreated control. The herbicide treatments were metsulfuron-methyl (Escort $\left.{ }^{\circledR}\right)$ applied at $12 \mathrm{~g} / \mathrm{ha}$ and clopyralid (Versatill@) applied at $600 \mathrm{~g} / \mathrm{ha}$. These were applied on 7 October 2002 with a $\mathrm{CO}_{2}$ powered backpack sprayer fitted with a $3 \mathrm{~m}$ boom and four TeeJet巴 11004 TTVP nozzles applying 300 litres water/ha at $330 \mathrm{kPa}$.

After treatment each plot was covered with a clear plastic tent that was divided into four $2 \mathrm{~m}$ segments. The tent was open at both ends to allow air circulation. On days 1, 3 and 7 after application of the herbicides, one of the randomly assigned tent segments was opened and about $15 \mathrm{~mm}$ of simulated rainfall applied via Gardena ${ }^{\mathrm{TM}}$ oscillating sprinklers during a $1 \mathrm{~h}$ period. One subplot remained covered at all times, receiving no rainfall. Runoff from the tents was absorbed into the $2 \mathrm{~m}$ buffers between plots and there was no lateral movement onto other plots. All the tents were removed 14 days after herbicide application and the plots exposed to normal rainfall events. Rainfall and soil temperatures were recorded hourly at the site using a portable weather station.

Determination of herbicide persistence and movement was by bioassay. For this, soil samples were collected from all plots on days $0,7,14,21,28,42$ and 56 after treatment. On each occasion four samples ( $75 \mathrm{~mm}$ diameter) were collected to $150 \mathrm{~mm}$ depth from each sub-plot. Each sample was divided into three $50 \mathrm{~mm}$ vertical sections on site and bulked according to depth and sub-plot. The soil samples were returned to the laboratory where they were thoroughly mixed and immediately used to plant out the bioassay species using $500 \mathrm{ml}$ punnets. For metsulfuron-methyl the bioassay species used were Italian ryegrass (Lolium multiflorum) and white mustard (Sinapis alba), while for clopyralid these were sunflower (Helianthus annuus) and subterranean clover (Trifolium subterraneum). The seedlings were thinned after emergence to between 4 and 8 per pot, depending on species, and grown in the glasshouse for 4-5 weeks. At this time the plants were scored for visual damage and the top growth was harvested, dried and weighed. All weights are expressed as percent of the untreated controls to normalise results. The bioassay method has been described in detail by Rahman (1989).

Concurrently, a standard calibration curve for each herbicide was established by growing the bioassay plants in pots of soil that had been spiked with known amounts of herbicide. These ranged from $0.0005-0.2 \mathrm{mg} / \mathrm{kg}$ dry soil for metsulfuron-methyl and from $0.005-1 \mathrm{mg} / \mathrm{kg}$ dry soil for clopyralid. The soil used for this was obtained from an untreated area adjacent to the site of the field trial and experimental procedures were as described for the bioassay plants above.

Herbicide residues in the field were estimated by comparing the weight reduction of bioassay plants in soil samples collected from the field with those of the plants grown in the calibration bioassay. Plant weights greater than $85 \%$ of the untreated control are generally considered to be not significantly different from untreated and this number $(85 \%)$ is set as the no observable effect level (NOEL) (Pestemer \& Günther 1993).

\section{RESULTS}

The standard calibration curves showed that Italian ryegrass was more sensitive than white mustard to low concentrations of metsulfuron-methyl in the soil. However, the logistic curve of the white mustard was much shorter than that of Italian ryegrass, as the white mustard was killed by concentrations of metsulfuron-methyl that were not lethal to the Italian ryegrass. For this reason only the results for Italian ryegrass are presented in Figure 1. For clopyralid, sunflower was found to be a better bioassay species because subterranean clover was less sensitive and more difficult to grow. Thus only the sunflower results for clopyralid are presented in Figure 1. Both herbicides are included in the same graph for ease of comparison of their relative activities. These results show that, using 
dry matter production of $85 \%$ of untreated as the NOEL, metsulfuron-methyl is about 40 times more active in the soil than clopyralid. At this threshold the limit of detection is $0.0025 \mathrm{mg} / \mathrm{kg}$ dry soil for metsulfuron and $0.1 \mathrm{mg} / \mathrm{kg}$ dry soil for clopyralid. For metsulfuron-methyl this is roughly equal to $1 \mathrm{~g} / \mathrm{ha}$ mixed into a $50 \mathrm{~mm}$ deep layer of soil. The clopyralid equivalent is about $40 \mathrm{~g} / \mathrm{ha}$.

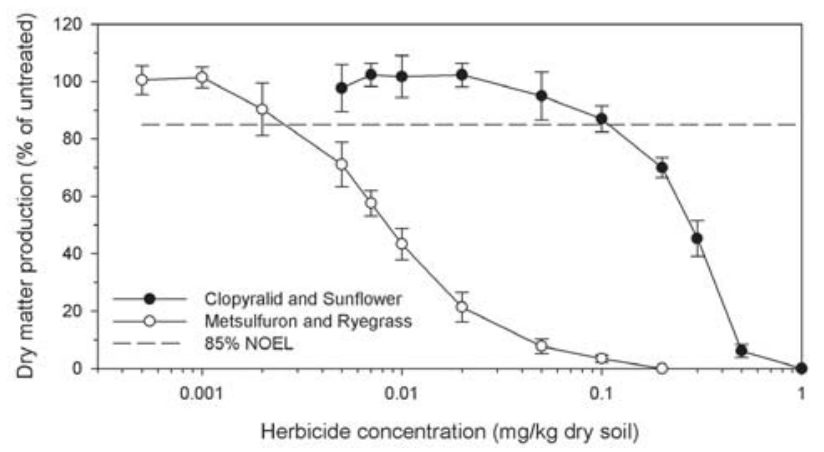

FIGURE 1: Standard calibration curves for the bioassay. Italian ryegrass was grown in soil that had been spiked with known amounts of metsulfuron-methyl while sunflower plants were grown in soil that had been spiked with known amounts of clopyralid. Values are expressed as dry matter production relative to plants grown in untreated soil $(\%)$. Error bars indicate \pm 1 SEM. The $85 \%$ no effect level (NOEL), below which significant weight reduction can occur, is also shown.

The bioassay results with Italian ryegrass for soil samples collected from the field trial are presented in Figure 2. Metsulfuron-methyl showed a high level of activity in the top $50 \mathrm{~mm}$ of the soil until significant quantities of rain fell after the Day 28 sampling (Fig. 2). However, by the time of the final sampling on Day 56, between $75 \%$ and $90 \%$ of the applied herbicide had disappeared. In the first 14 days after application there was no indication that the $15 \mathrm{~mm}$ of simulated rain applied to certain subplots had any effect on the amount of metsulfuron-methyl residues found in the top $50 \mathrm{~mm}$ soil layer. Similarly, there is very little indication that significant amounts of metsulfuron-methyl were leached into the 50-100 mm depth as a result of the applied rainfall in the first 7 days after application. This is surprising as it appears that the first natural rainfall event after the covers were removed (Day 18), which at $12 \mathrm{~mm}$ was a similar amount to the simulated rain, moved detectable and significant amounts of metsulfuron-methyl into the 50-100 mm soil layer. However, over the subsequent 7 days (to Day 28) when there was very little rain, the leached residues mostly disappeared. Then, on Day 42, more herbicide residues were found in this soil layer after there had been further heavy rain (Fig. 2). No phytotoxic residues of metsulfuron-methyl residues were found in the $100-150 \mathrm{~mm}$ soil layer.

The bioassay results with sunflower for soil samples collected from the field trial are presented in Figure 3. Residues of clopyralid in the top $50 \mathrm{~mm}$ of soil killed all the sunflower plants for the first 21 days after application but after that time residues rapidly disappeared and by Day 56 less than $10 \%$ of the applied herbicide remained (Fig. 3). No significant residues of clopyralid were detected in either the $50-100 \mathrm{~mm}$ or the $100-150$ $\mathrm{mm}$ soil layer at any stage. 


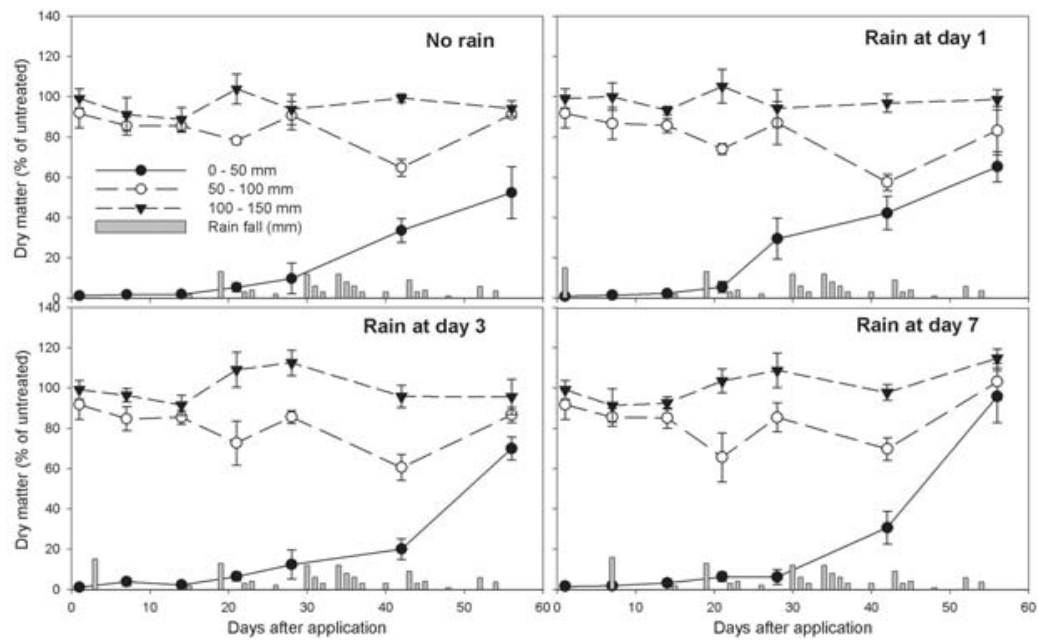

FIGURE 2: Italian ryegrass dry matter production from stratified soil samples $(0-50 \mathrm{~mm}, 50-100 \mathrm{~mm}$ or $100-150 \mathrm{~mm})$ collected from plots that were exposed to simulated rain at either 1,3 or 7 days after application of the herbicide metsulfuron-methyl. Values are expressed as dry matter production relative to plants grown in untreated soil (\%). Error bars indicate $\pm 1 \mathrm{SEM}$. Daily rainfall $(\mathrm{mm})$ is overlaid as a histogram.

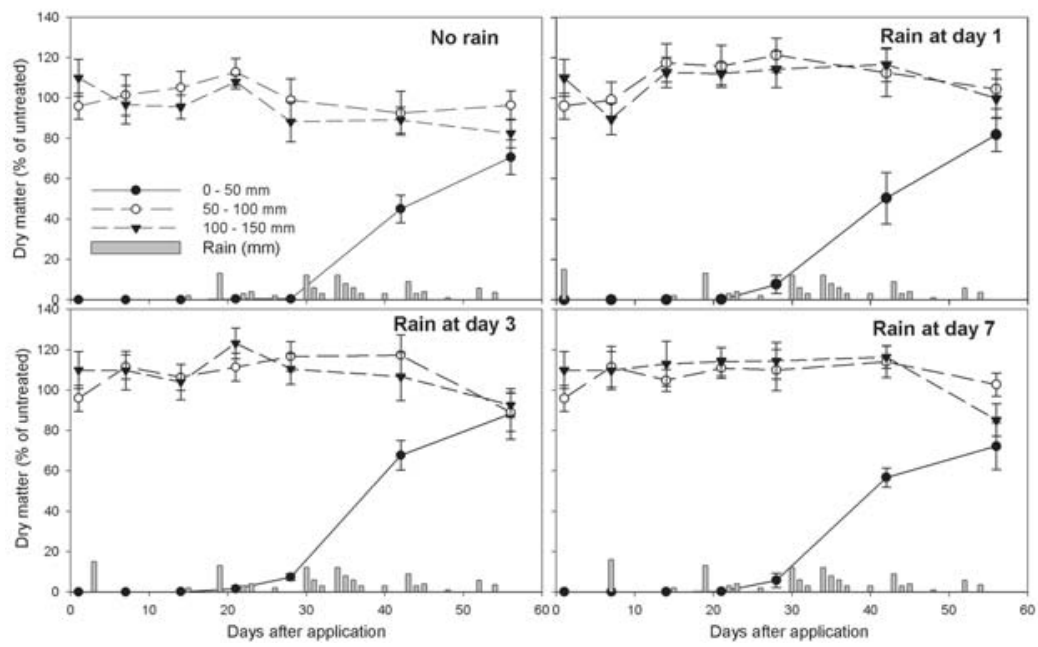

FIGURE 3: Sunflower dry matter production from stratified soil samples $(0-50 \mathrm{~mm}$, $50-100 \mathrm{~mm}$ or $100-150 \mathrm{~mm}$ ) collected from plots that were exposed to simulated rain at either 1,3 or 7 days after application of the herbicide clopyralid. Values are expressed as dry matter production relative to plants grown in untreated soil (\%). Error bars indicate \pm 1 SEM. Daily rainfall $(\mathrm{mm})$ is overlaid as a histogram. 


\section{DISCUSSION}

The results of this study are in keeping with studies conducted previously in New Zealand. Rahman et al. (1991) found that metsulfuron-methyl applied at $12 \mathrm{~g} / \mathrm{ha}$ could not be detected by bioassay methods at 63 days after application to a Horotiu silt loam soil in the Waikato region. In laboratory studies with leaching columns, Rahman \& James (1989) found that metsulfuron-methyl (20 g/ha) was leached about $160 \mathrm{~mm}$ down the column by the equivalent of $100 \mathrm{~mm}$ of rain applied immediately after placement of the herbicide. In a similar experiment using Horotiu silt loam soil Rahman et al. (1997) found that with an initial dose of $30 \mathrm{~g} / \mathrm{ha}$ and the equivalent of $60 \mathrm{~mm}$ of rain metsulfuron-methyl was detected $80 \mathrm{~mm}$ down the column. In the field study reported here, total rainfall at the site (including the simulated rainfall) totalled $118 \mathrm{~mm}$ but was spread over a considerably longer period of time and would therefore not be expected to have the same impact on leaching. This was demonstrated with rainfall events of about $10-20 \mathrm{~mm}$ resulting in only small movement of metsulfuron-methyl out of the top $50 \mathrm{~mm}$ layer of soil. Although it appears that rainfall in general could enhance dissipation of metsulfuron-methyl by distributing the herbicide through the profile it was not leached below $100 \mathrm{~mm}$ and early rain within the first few days of application appeared to have no effect on this process.

In a trial where the persistence of $0.56 \mathrm{~kg}$ acid equivalent $/$ ha clopyralid was determined after application to bare ground prior to a cereal crop, it was found that bioassay methods detected significant residues after 287 days (Tanphiphat \& Burrill 1987). That study also found that significant quantities of clopyralid leached into the $100-200 \mathrm{~mm}$ soil layer but that these had dissipated by Day 220. Conversely, in trials on typical New Zealand pastures, Rahman et al. (1981) found the safe plant back period for $400 \mathrm{~g} / \mathrm{ha}$ clopyralid was 49-56 days using subterranean clover as a bioassay species. Also, Ahmad et al. (2003) demonstrated that when clopyralid was applied to grass at $600 \mathrm{~g} / \mathrm{ha}$, there were no detectable residues after 56 days and that the half-life was 5 days. They also found that when clopyralid was applied to bare ground (all grass removed to soil level) that the half-life extended to 13 days. The results presented in the current study are in agreement with those of Ahmad et al. (2003) but add further information, in that since no clopyralid was leached from the root zone of the soil, it can be assumed that herbicide dissipation was entirely by degradation. As the main degradation pathway for clopyralid is microbial (Ahmad et al. 2003) then high microbial populations supported by healthy pastures are apparently contributing to the short residual activity of clopyralid in pasture.

\section{REFERENCES}

Ahmad, R.; James, T.K.; Rahman, A.; Holland, P.T. 2003: Dissipation of the herbicide clopyralid in an allophanic soil: laboratory and field studies. J. Environ. Sci. and Health, Part B - Pesticides, Food Contaminants and Agricultural Wastes 6: 683695.

James, T.K.; Klaffenbach, P.; Holland, P.T.; Rahman, A. 1995: Degradation of the sulfonylurea herbicides primisulfuron-methyl and metsulfuron-methyl in soil. Weed Res. 35: 113-120.

James, T.K.; Rahman, A. 2001: Bioavailability of metsulfuron-methyl in soil under permanent pasture. Proc. Bioavailability Conf. Adelaide, Australia. Pp. 92-93.

James, T.K.; Rahman, A.; Cornwell, M.J. 1999: Pasture tolerance to the herbicide metsulfuron-methyl. Proc. 52nd N.Z. Plant Prot. Conf.: 240-244.

O’Connor, B. 2004: Novachem Manual. Novachen Services Ltd, Palmerston North, New Zealand. $472 \mathrm{p}$.

Pestemer, W.; Günther, P. 1993: No-observable-effect level (NOEL). In: Streibig, J.C.; Kudsk, P. ed. Herbicide Bioassays. CRC Press, Boca Raton. Pp. 137-152.

Rahman, A.1989: Sensitive bioassays for determining residues of sulfonylurea herbicides in soil and their availability to crop plants. In: Munawar, M.; Dixon, G.; Mayfield, C.I.; Reynoldson, T.; Sadar, M.H. ed. Environmental Bioassay Techniques and their Application. Hydrobiologia 188/189: 367-375. 
Rahman, A.; Baki, B.B.; James, T.K. 1997: Mobility of four sulfonylurea herbicides in some New Zealand and Malaysian soils. Proc. 16th Asian-Pacific Weed Sci. Soc. Conf.: 139-143.

Rahman, A.; James, T.K. 1989: Comparative mobility of nine sulfonylurea herbicides in soil columns. Proc. 12th Asian-Pacific Weed Sci. Soc. Conf.: 213-217.

Rahman, A.; James, T.K.; Martin, P.; Fullerton, D.K. 1991: Persistence of metsulfuron in different soils. Proc. 44th N. Z. Weed and Pest Cont. Conf.: 99-104.

Rahman, A.; Manson, B.E.; Sanders, P. 1981: Persistence of 3,6-dichloropicolinic acid and dicamba residues in the soil. Proc. 34th N. Z. Weed and Pest Cont. Conf.: 126129.

Sarmah, A.K.; Kookana, R.S.; Alston, A.M. 2000: Leaching and degradation of triasulfuron, metsulfuron-methyl, and chlorsulfuron in alkaline soil profiles under field conditions. Aust. J. Soil Res. 38: 617-631.

Tanphiphat, K.; Burrill, L.C. 1987: Persistence of clopyralid in soil. Proc. West. Soc. Weed Sci. 40: 75. 